\title{
Efficacy and safety of an open lung ventilation strategy with staircase recruitment followed by comparison on two different modes of ventilation, in moderate ARDS in cirrhosis: A pilot randomized trial
}

\author{
Goel Vibha $M D^{1}$, Vandana Saluja $M D^{1}$, Mitra Lalita Gouri MD¹, Kumar Guresh MPhil PhD², \\ Aggarwal Prashant MD', Maiwall Rakhi DM³
}

\begin{abstract}
G Vibha, V Saluja, ML Gouri, K Guresh, A Prashant, M Rakhi. Efficacy and safety of an open lung ventilation strategy with staircase recruitment followed by comparison on two different modes of ventilation, in moderate ARDS in cirrhosis: A pilot randomized trial. Can J Respir Ther 2021;57:105-112. doi: 10.29390/cjrt-2021-011.

Background: Mechanical ventilation in cirrhosis with acute respiratory distress syndrome (ARDS) is not widely studied. We aimed to study the effect of the staircase recruitment manoeuvre followed by two different modes of ventilation.

Methods: Thirty patients with cirrhosis with moderate ARDS underwent the staircase recruitment manoeuvre followed by randomisation to volume control or pressure control group.

Results: The $\mathrm{PaO}_{2} / \mathrm{FiO}_{2}$ ratio showed a significant improvement in both the groups after recruitment. The improvement was significantly higher in the pressure control ventilation (PCV) group at the end of the first hour as compared to the volume control ventilation (VCV) group. However, this difference was not significant at the end of 6 and $12 \mathrm{~h}$. In the PCV group it improved from $118.47 \pm 10.21$ at baseline to $189.87 \pm 55.1812 \mathrm{~h}$ post-recruitment. In the VCV group it improved from $113.79 \pm 13.22$ at baseline to $180.93 \pm 81.971$. Static lung compliance also improved in both the groups significantly $(P<$ 0.001). The PCV group showed an improvement from $25.42 \pm 11.94 \mathrm{~mL} / \mathrm{cm} \mathrm{H}_{2} \mathrm{O}$ at baseline to $29.51 \pm 14.58 \mathrm{~mL} / \mathrm{cm} \mathrm{H}_{2} \mathrm{O}$. In the VCV group the lung compliance improved from $24.78 \pm 4.87 \mathrm{~mL} / \mathrm{cm} \mathrm{H}_{2} \mathrm{O}$ to $31.31 \pm 10.88 \mathrm{~mL} / \mathrm{cm} \mathrm{H}_{2} \mathrm{O}$.

Conclusion: This study shows that stepwise recruitment manoeuvre is an effective rescue therapy to improve oxygenation in cirrhosis with moderate ARDS. PCV may have an advantage over VCV in terms of better oxygenation.
\end{abstract}

Key Words: cirrhosis; ARDS; recruitment; ventilation mode

\section{INTRODUCTION}

Patients with end-stage liver disease are at risk for developing acute respiratory failure and hypoxemia secondary to hepatopulmonary syndrome, portopulmonary hypertension [1]. The presence of an exaggerated inflammatory response with a relative immunocompromised state predisposes to acute lung injury and pneumonia [2]. Respiratory abnormalities like chest wall oedema and pleural effusions (hepatic hydrothorax) decrease thoracic compliance [3]. Presence of ascites results in cephalad displacement of the diaphragm. This also reduces the respiratory muscle efficiency and increases the work of breathing [4]. This results in atelectasis and worsening pulmonary gas exchange. Acute respiratory distress syndrome (ARDS) is one of the main reasons for intensive care unit admission and mortality [2]. Mechanical ventilation is a life-supporting intervention that aims to maintain gas exchange [5]. It allows time for the lungs to heal, but it is invasive and can result in lung injury [6]. It is uncertain whether the ventilator-related injury can be reduced if the pressure delivered by the ventilator with each breath is controlled or whether the volume of air delivered by each breath is limited [7].
A Cochrane review in 2018 has suggested that the current data are insufficient to recommend a particular mode. The authors have also called for more studies to provide reliable evidence.

Shear stress contributes to ventilator-induced lung injury (VILI) [8]; hence the "open lung" concept has been advocated to keep the lung open. It consists of a recruitment manoeuvre to open the lung followed by a high positive end expiratory pressure (PEEP) application to maintain alveolar stability [8]. It has been suggested that a pressure of $45-60 \mathrm{~cm} \mathrm{H}_{2} \mathrm{O}$ is required to overcome the alveolar retractile force and the compressing force on the alveolus by surrounding lung tissue [9].

Metanalysis has concluded that recruitment manoeuvres result in improvement in oxygenation but may cause negative hemodynamic consequences in ARDS [10]. However, the data with regards to mechanical ventilation is nonexistent for patients with cirrhosis [11]. Therefore, the primary objective of the study was to assess the efficacy and safety of the staircase recruitment manoeuvre (SRM) in moderate ARDS in cirrhosis. The secondary objective was to study the impact of two different modes of ventilation on oxygenation post recruitment.

${ }^{1}$ Department of Critical Care, Institute of Liver and Biliary Sciences, New Delhi, India

${ }^{2}$ Department of Biostatistics, Institute of Liver and Biliary sciences, New Delhi, India

${ }^{3}$ Department of Hepatology, Institute of Liver and Biliary Sciences, New Delhi, India

Correspondence: Vandana Saluja, Institute of Liver and biliary sciences, Sector D 1, Vasant Kunj, New Delhi-110070. Tel: 011 46300000, E-mail: vandypats@ yahoo.co.in

Published online at https://www.cjrt.ca on 20 July 2021 


\section{METHODS}

This prospective, pilot randomised controlled trial was conducted after approval by the Institutional Ethics Committee (Number: IEC/2017/51/ NA07) from 1 October 2017 to 30 January 2018. All patients gave written informed consent, as per the declaration of Helsinki and good clinical practice guidelines. Thirty adult cirrhotic patients who received mechanical ventilation for the first time in our institute and who satisfied Berlin criteria for moderate acute respiratory distress syndrome with a requirement of $\mathrm{FiO}_{2}>50 \%$ with $\mathrm{pO}_{2}<85 \mathrm{mmHg}$ after $6 \mathrm{~h}$ of intubation and mechanical ventilation were included. Patients were excluded in case of cardiogenic pulmonary oedema, history of arrhythmia, preexisting chronic lung disease, hepatopulmonary syndrome, portopulmonary hypertension, anatomic chest wall abnormalities, and increased intracranial tension.

Both groups of patients underwent the following investigations on intensive care unit (ICU) admission: haemogram, renal and liver function tests, blood sugar fasting, arterial blood gas, and chest X-ray. In all 30 patients, SRM was initiated. All patients were ventilated with the Extend XT ventilator (Air Liquide medical systems, France). Prior to initiation of the SRM, all patients were on pressure control mode of ventilation. Since there is no standard technique, the technique reported by Hodgson et al. was followed [12]. Sedation was given as per ICU protocol. The patients were paralysed with and injection of atracurium. Recruitment was done once; however, if arterial blood gas (ABG) analysis showed a decrease in $\mathrm{PaO}_{2}$ (partial pressure of arterial oxygen) at the same $\mathrm{FiO}_{2}$ (fraction of inspired oxygen), recruitment was done again. The inspiratory pressure was set to $15 \mathrm{~cm} \mathrm{H}_{2} \mathrm{O}$, and PEEP was increased in a stepwise manner to 20, then 30 , and then $40 \mathrm{~cm} \mathrm{H}_{2} \mathrm{O}$ every 2 min and then reduced to 25 , then 22 , then 19 , or then $15 \mathrm{~cm} \mathrm{H}_{2} \mathrm{O}$ every
3 min or until a decrease in $\mathrm{SaO}_{2} \geq 1 \%$ from maximum $\mathrm{SaO}_{2}$ was observed. This was defined as the derecruitment point. PEEP was then increased to $40 \mathrm{~cm} \mathrm{H}_{2} \mathrm{O}$ for $1 \mathrm{~min}$ and returned to a PEEP level $2 \mathrm{~cm} \mathrm{H}_{2} \mathrm{O}$ above the derecruitment point (which was then defined as optimal PEEP).

Immediately post-SRM, the patients were randomized to either volume control ventilation (VCV) or pressure control ventilation (PCV). The patients were randomly allocated to either group using computer generated, random numbers from a biostatistician not directly involved in the study. Patients were randomized to either of the two groups in 1:1 ratio. Blinding was not possible for technical reasons.

Both groups were continued on sedation. Patients were monitored for changes in oxygenation; lung compliance; vitals; vasopressor inotropic score (VIS) [13]; ventilator parameters $1 \mathrm{~h}, 6 \mathrm{~h}$, and 12-h post-SRM and for length of mechanical ventilation; length of ICU stay; and mortality. The primary endpoint was improvement in oxygenation and static lung compliance lasting for at least for $12 \mathrm{~h}$ post-recruitment on both the modes of ventilation.

Secondary endpoints were: failure of recruitment in terms of failure to improve oxygenation; adverse effects of recruitment like hypotension, arrhythmia, desaturation, tachycardia, bradycardia; pneumothorax requiring termination of recruitment manoeuvre; and duration of mechanical ventilation

Statistical Package for the Social Science (SPSS) version 16, (SPSS-16, IBM, Chicago, USA) was used for analysing the data. Data were reported as proportions or mean $\pm \mathrm{SD}$. Chi-square test or Fisher exact test was used for categorical variables. Normally distributed continuous variables were compared using the Student t-test (unpaired data) to analyze the significant effect in patients. The sample size was one of convenience since this was a pilot study.

\section{FIGURE 1}

\section{Participant flow in the study.}

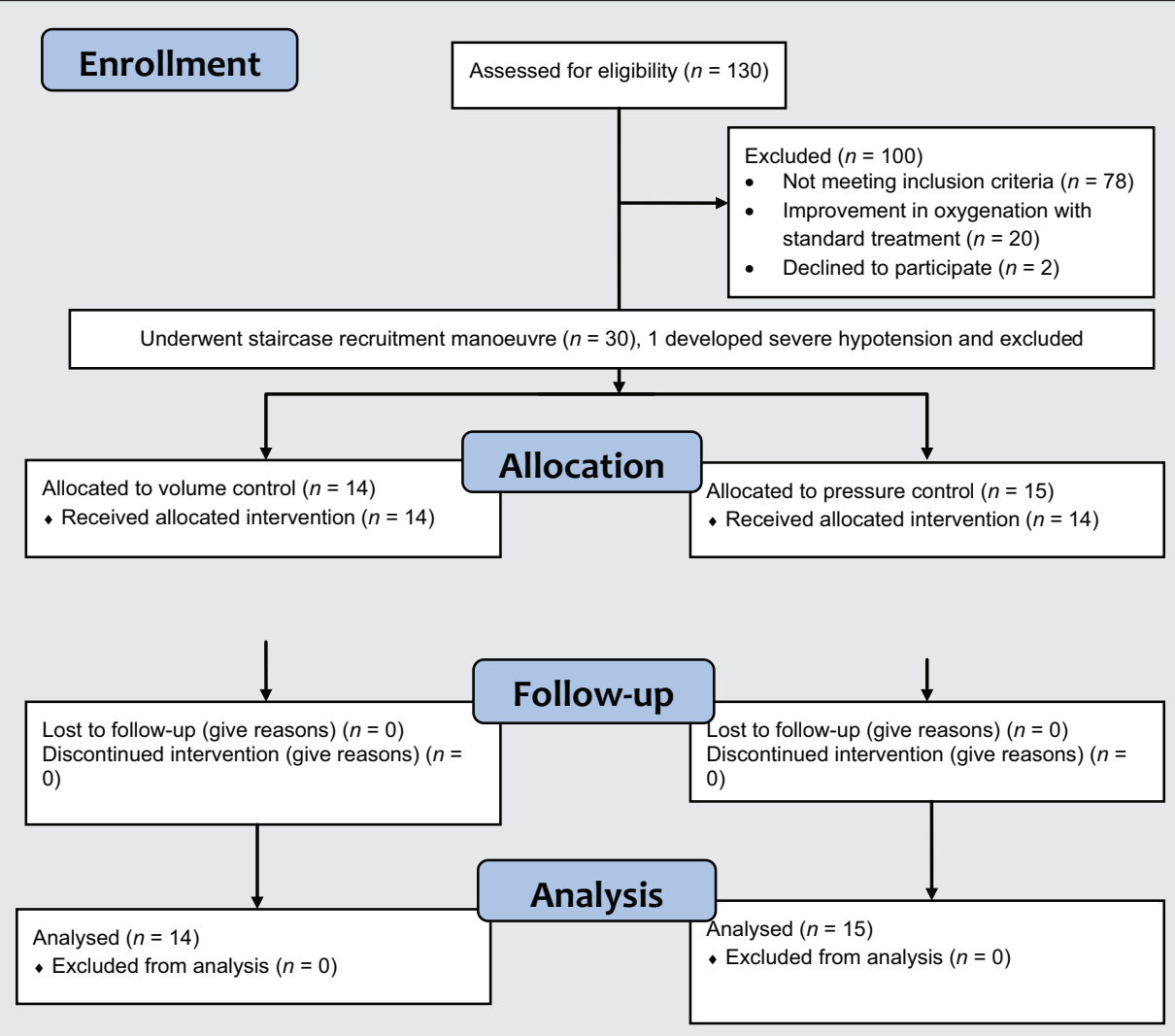




\section{RESULTS}

The allocation of patients is shown in the CONSORT (Consolidated Standards of Reporting Trials) diagram (Figure 1). The baseline demographic, disease severity scores, blood gas values, ventilator, and hemodynamic parameters were comparable in both the groups (Table 1). Admitted patients had high MELD (model for end-stage liver disease) and SOFA (sequential organ failure assessment) scores score in both the groups. No significant differences in terms of age, sex, oxygenation, ventilatory parameters, or hemodynamic parameters were present. The $\mathrm{PaO}_{2} / \mathrm{FiO}_{2}$ ratio was comparable at baseline in both groups $(P=0.29)$. The vasopressor support was comparable in both groups $(P=0.54)$. Presence of infection as a possible precursor to ARDS was present in $60 \%$ of patients in the PCV group and in $40 \%$ of patients in the VCV group, $P=0.28$.

SRM showed a significant improvement in $\mathrm{PaO}_{2}$ in the PCV and VCV group at the end of $12 \mathrm{~h}$, but there was no difference between both groups $(P=0.73)$ (Table 2, Figure 2). Both groups showed a significant improvement in $\mathrm{PaO}_{2} / \mathrm{FiO}_{2}$ ratio at the end of $12 \mathrm{~h}$. The improvement in $\mathrm{PaO}_{2} /$ $\mathrm{FiO}_{2}$ ratio was significantly higher in the PCV group at the end of the first hour as compared to the VCV group (Table 2, Figure 3). The PEEP requirement was significantly higher in the volume control group at the end of $6 \mathrm{~h}$ and $12 \mathrm{~h}$ as compared to the pressure control group. Both the groups required an increase in PEEP from the baseline after the recruitment manoeuvre, which showed a trend towards significance $(P=0.05)$ (Table 2, Figure 4). The plateau pressure also reduced significantly in both

\section{TABLE 1}

Baseline demographic, clinical, blood gas, and ventilatory parameters of patients enrolled

\begin{tabular}{|c|c|c|c|}
\hline Characteristics & $\begin{array}{l}\text { PCV group } \\
\quad(n=15)\end{array}$ & $\begin{array}{l}\text { VCV group } \\
\quad(n=15)\end{array}$ & $\boldsymbol{P}$ \\
\hline Age (years) & $46.87 \pm 12.72$ & $50.20 \pm 14.45$ & 0.5 \\
\hline BMI & $26.65 \pm 2.91$ & $24.82 \pm 3.77$ & 0.14 \\
\hline SOFA & $12.27 \pm 3.150$ & $12.40 \pm 2.798$ & 0.90 \\
\hline APACHE & $39 \pm 10.351$ & $40.67 \pm 6.673$ & 0.60 \\
\hline MELD & $29.33 \pm 9.217$ & $24.6 \pm 9.395$ & 0.17 \\
\hline CTP & $12.87 \pm 1.807$ & $13.40 \pm 5.316$ & 0.71 \\
\hline \multicolumn{4}{|c|}{ ABG parameters and Ventilatory parameters } \\
\hline $\mathrm{pH}$ & $7.35 \pm 0.05$ & $7.33 \pm 0.10$ & 0.53 \\
\hline $\mathrm{HCO}_{3}(\mathrm{mmol} / \mathrm{L})$ & $19.52 \pm 6.85$ & $18.96 \pm 4.66$ & 0.81 \\
\hline $\mathrm{Na}(\mathrm{mmol} / \mathrm{L}$ & $136.00 \pm 6.72$ & $132.73 \pm 9.77$ & 0.33 \\
\hline $\mathrm{K}(\mathrm{mmol} / \mathrm{L})$ & $4.600 \pm 0.93$ & $4.227 \pm 0.96$ & 0.34 \\
\hline Lactate $(\mathrm{mmol} / \mathrm{L})$ & $6.45 \pm 6.15$ & $6.173 \pm 6.35$ & 0.90 \\
\hline $\mathrm{FiO}_{2}$ & $50.36 \pm 14.70$ & $50.80 \pm 14.45$ & 0.93 \\
\hline $\mathrm{PaO}_{2}(\mathrm{~mm} \mathrm{Hg})$ & $79.64 \pm 12.55$ & $71.06 \pm 20.45$ & 0.18 \\
\hline $\mathrm{PCO}_{2}(\mathrm{~mm} \mathrm{Hg})$ & $39.32 \pm 8.77$ & $40.84 \pm 8.86$ & 0.64 \\
\hline $\mathrm{PaO}_{2} / \mathrm{FiO}_{2}$ & $118.47 \pm 10.21$ & $113.79 \pm 13.22$ & 0.29 \\
\hline $\operatorname{PEEP}\left(\mathrm{cm} \mathrm{H}_{2} \mathrm{O}\right)$ & $6.60 \pm 0.91$ & $7.27 \pm 1.71$ & 0.19 \\
\hline Tidal Volume (ml) & $470.20 \pm 150.09$ & $488.21 \pm 47.37$ & 0.67 \\
\hline Plateau pressure $\left(\mathrm{cm} \mathrm{H}_{2} \mathrm{O}\right)$ & $25 \pm 2.50$ & $26.64 \pm 2.46$ & 0.08 \\
\hline \multicolumn{4}{|l|}{ Vitals } \\
\hline Heart rate (beats per minute) & $90.6 \pm 5.83$ & $87.33 \pm 7.57$ & 0.19 \\
\hline MAP $(\mathrm{mm} \mathrm{Hg})$ & $76.07 \pm 22.42$ & $83.18 \pm 27.50$ & 0.48 \\
\hline VIS & $12.27 \pm 10.81$ & $9.79 \pm 10.98$ & 0.54 \\
\hline $\begin{array}{l}\text { Presence of infection on } \\
\text { day of intubation }\end{array}$ & $9 / 15(60 \%)$ & $6 / 15(40 \%)$ & 0.28 \\
\hline
\end{tabular}

Data are $n(\%)$ or mean \pm S.D.

Note: $A P A C H E=$ acute physiology and chronic health evaluation; $B M I=$ body mass index; CTP = Child Turcotte Pugh score; $\mathrm{FiO}_{2}=$ fraction of inspired oxygen; $\mathrm{HCO}_{3}=$ bicarbonate; $\mathrm{cm} \mathrm{H}_{2} \mathrm{O}=$ centimeters of water; $\mathrm{K}=$ potassium $M A P=$ mean blood pressure; $M E L D=$ model for end stage liver disease; $\mathrm{mm} \mathrm{Hg}=$ millimeters of Mercury; $\mathrm{Na}=$ Sodium $\mathrm{PaO}_{2}=$ partial pressure of arterial oxygen; $\mathrm{PCO}_{2}=$ partial pressure of arterial carbon dioxide; $P$ plat $=$ plateau pressure; $P C V=$ pressure controlled ventilation; $P E E P=$ positive end expiratory pressure; $S D$ = standard deviation; SOFA = sequential organ failure score; $T V=$ tidal volume $;$ VIS = vasopressor inotropic score; $A B G=$ arterial blood gas; $V C V=$ volume control ventilation . the groups, $(P<0.05)$ with no difference between the groups (Table 2, Figure 5). Likewise, the static compliance also improved in both the groups, which was sustained till the end of $12 \mathrm{~h}$ after recruitment; however, there was no difference between both groups (Table 2, Figure 6).

One patient developed severe hypotension and bradycardia during the recruitment manoeuvre, so it was abandoned. There were no significant changes in heart rate and mean arterial pressure between the two groups or over time (Table 3). There was no significant change in the vasopressor inotrope score seen after the recruitment. (Table 3). Also, there was no difference between both groups. There was no significant difference in the length of mechanical ventilation or outcome between the two groups (Tables 4, 5).

\section{DISCUSSION}

Acute respiratory distress syndrome in cirrhosis is associated with increased mortality [14]. Deaths occurring early in the course of ARDS are mainly associated with refractory hypoxemia and late deaths are associated with progressive multiorgan failure [15]. Even without severe systemic disease, gas exchange abnormalities are common in cirrhosis due to ventilation perfusion mismatching and intrapulmonary shunting. Ascites, pleural effusions, and basal atelectasis can further worsen oxygenation [11].

Various studies on ARDS like low tidal volume ventilation, high PEEP, use of neuromuscular blockers, and recruitment strategies aim to improve oxygenation and minimize lung injury. The use of low tidal ventilation and high PEEP are standard practices in ARDS in patients with cirrhosis to improve oxygenation [2]. But the frequent presence of shock, coagulopathy, and distended abdomen preclude the use of prone positioning or extracorporeal membrane oxygenation in cases of refractory hypoxia.

To our knowledge, this the first study to evaluate the open lung ventilation strategy with staircase recruitment in patients with cirrhosis. This was similar to a study by Hodgson et al. [12] where using a decremental PEEP identified the optimal PEEP for each patient and helped in improving oxygenation and compliance. Recruitment manoeuvres are a voluntary strategy to increase transpulmonary pressure transiently to open the poorly aerated alveoli. The rationale of use in ARDS is based on the fact that the lung is derecruited (baby lung) and recruitment is possible once the minimum amount of pressure (critical opening pressure) required to maintain patency of alveoli has been reached. This results in an increase in the aerated lung mass and prevents repeated opening and closure of alveoli [16]. Other methods of recruitment like sigh and sustained inflation have been studied. Frequent occurrences of sigh episodes with high plateau pressure have raised safety concerns about the "sigh" technique [17]. Overdistension with worsening morphological and functional heterogeneity of the lung were side effects of the sustained inflation technique [18]. Hodgson et al. [12] found a reduction in the IL-8 and TNF alpha levels in patients who underwent the SRM. They required lesser episodes of rescue therapies with a lower PEEP compared with the control group.

In our study, lung compliance improved similarly but significantly in both groups over time, indicating that lung recruitment was possible and sustained throughout the study. Hodgson et al. [12] reported the improvement in lung compliance from $45 \mathrm{~mL} / \mathrm{cm} \mathrm{H}_{2} \mathrm{O}$ to $49 \mathrm{~mL} / \mathrm{cm}$ $\mathrm{H}_{2} \mathrm{O}$. The baseline compliance in our patients was approximately $25 \mathrm{~mL} / \mathrm{cm} \mathrm{H}_{2} \mathrm{O}$ which improved to around $30 \mathrm{~mL} / \mathrm{cm} \mathrm{H}_{2} \mathrm{O}$. This is because patients with cirrhosis have a baseline reduced lung compliance due to the presence of ascites, atelectasis with pleural effusion, and intrathoracic chances of volume overload. Though we have not recorded these factors in individual patients, these could have been the contributing factors to the overall reduced compliance in our patients.

We found that the recruitment manoeuvre increased the lung compliance, $\mathrm{PaO}_{2}$, and $\mathrm{PaO}_{2} / \mathrm{FiO}_{2}$ ratios significantly till $12 \mathrm{~h}$ after the procedure. This improvement could be attributed to the SRM as well as the increased levels of PEEP in both the groups. The improvement in the $\mathrm{PaO}_{2} / \mathrm{FiO}_{2}$ ratio was significant in the PCV group in the first hour. Though the $\mathrm{PaO}_{2} / \mathrm{FiO}_{2}$ ratios were comparable in both the groups at the 
Vibha et al.

TABLE 2

Ventilatory parameters before and after recruitment

\begin{tabular}{|c|c|c|c|c|c|c|}
\hline & & $\mathrm{Oh}$ & $1 \mathrm{~h}$ & $6 \mathrm{~h}$ & $12 \mathrm{~h}$ & $P$ \\
\hline \multirow[t]{2}{*}{$\mathrm{PaO}_{2}($ mean $\pm \mathrm{SD})$} & PCV & $79.64 \pm 12.55$ & $109.07 \pm 34.85$ & $93.98 \pm 24.82$ & $97.55 \pm 33.71$ & $<0.05$ \\
\hline & VCV & $71.06 \pm 20.45$ & $93.207 \pm 25.88$ & $95.91 \pm 22.29$ & $115.29 \pm 30.07$ & $<0.05$ \\
\hline$P$ & & 0.18 & 0.17 & 0.82 & 0.14 & \\
\hline \multirow{2}{*}{$\mathrm{PCO}_{2}($ mean $\pm \mathrm{SD})$} & PCV & $39.32 \pm 8.77$ & $38.387 \pm 7.92$ & $38.26 \pm 8.40$ & $38.26 \pm 8.89$ & 0.63 \\
\hline & VCV & $40.84 \pm 8.86$ & $38.05 \pm 10.29$ & $41.43 \pm 7.69$ & $40.71 \pm 8.05$ & 0.69 \\
\hline$P$ & & 0.64 & 0.92 & 0.30 & 0.44 & \\
\hline \multirow[t]{2}{*}{$\mathrm{PaO}_{2} / \mathrm{FiO}_{2}($ mean $\pm \mathrm{SD})$} & $\mathrm{PCV}$ & $118.47 \pm 10.218$ & $185.67 \pm 52.782$ & $179.13 \pm 48.264$ & $189.87 \pm 55.187$ & $<0.05$ \\
\hline & VCV & $113.79 \pm 13.221$ & $129.29 \pm 42.253$ & $144.64 \pm 50.118$ & $180.93 \pm 81.971$ & $<0.05$ \\
\hline$P$ & & 0.29 & $<0.05$ & 0.07 & 0.73 & \\
\hline \multirow[t]{2}{*}{ Compliance (mean \pm SD) } & PCV & $25.42 \pm 11.94$ & $25.95 \pm 11.6$ & $28.78 \pm 13.61$ & $29.51 \pm 14.58$ & $<0.05$ \\
\hline & VCV & $24.78 \pm 4.87$ & $27.05 \pm 4.06$ & $29.83 \pm 5.12$ & $31.31 \pm 10.88$ & $<0.05$ \\
\hline$P$ & & 0.85 & 0.73 & 0.78 & 0.66 & \\
\hline \multirow[t]{2}{*}{ PEEP (mean \pm SD) } & PCV & $6.60 \pm 0.91$ & $8.53 \pm 0.83$ & $8.47 \pm 0.91$ & $8.53 \pm 1.12$ & 0.05 \\
\hline & VCV & $7.27 \pm 1.71$ & $9.20 \pm 1.65$ & $9.60 \pm 1.72$ & $9.60 \pm 1.72$ & 0.05 \\
\hline$P$ & & 0.19 & 0.17 & $<0.05$ & 0.05 & \\
\hline \multirow[t]{2}{*}{ Plateau pressure (mean $\pm \mathrm{SD}$ ) } & PCV & $25.00 \pm 2.50$ & $26.13 \pm 2.99$ & $25.40 \pm 4.23$ & $24.67 \pm 3.67$ & $<0.05$ \\
\hline & VCV & $26.64 \pm 2.46$ & $27.21 \pm 2.19$ & $26.00 \pm 2.85$ & $25.14 \pm 2.82$ & $<0.05$ \\
\hline$P$ & & 0.08 & 0.28 & 0.66 & 0.44 & \\
\hline \multirow[t]{2}{*}{ Tidal Volume (mean $\pm \mathrm{SD})$} & PCV & $470.20 \pm 150.09$ & $460.26 \pm 111.32$ & $468.66 \pm 121.50$ & $455.20 \pm 124.68$ & 0.53 \\
\hline & VCV & $488.21 \pm 47.37$ & $482.50 \pm 42.09$ & $480.35 \pm 43.16$ & $480.00 \pm 43.36$ & 0.53 \\
\hline$P$ & & 0.67 & 0.48 & 0.73 & 0.48 & \\
\hline \multirow[t]{2}{*}{$\mathrm{pH}($ mean $\pm \mathrm{SD})$} & $\mathrm{PCV}$ & $7.35 \pm 0.05$ & $7.37 \pm 07$ & $7.36 \pm 0.08$ & $7.35 \pm 0.10$ & 0.76 \\
\hline & VCV & $7.33 \pm 0.10$ & $7.33 \pm 0.16$ & $7.31 \pm 0.11$ & $7.3221 \pm 0.12$ & 0.76 \\
\hline$P$ & & 0.53 & 0.35 & 0.17 & 0.40 & \\
\hline
\end{tabular}

Note: $S D=$ standard deviation; $P C V=$ pressure control ventilation; $V C V=$ volume control ventilation; $P E E P=$ positive end expiratory pressure; $P$ aO ${ }_{2}=$ partial pressure of arterial oxygen; $\mathrm{PCO}_{2}=$ partial pressure of arterial carbon dioxide; $\mathrm{FiO}_{2}=$ Fraction of inspired oxygen.

" 0 " $h$ values are taken just before recruitment manouvre.

$1 \mathrm{~h}, 6 \mathrm{~h}$ and $12 \mathrm{~h}$ values at those at the respective time after recruitment.

\section{FIGURE 2}

Trend of partial pressure of oxygen (PO2) in arterial blood gas after recruitment manouvre in pressure control ventilation and volume control ventilation groups.

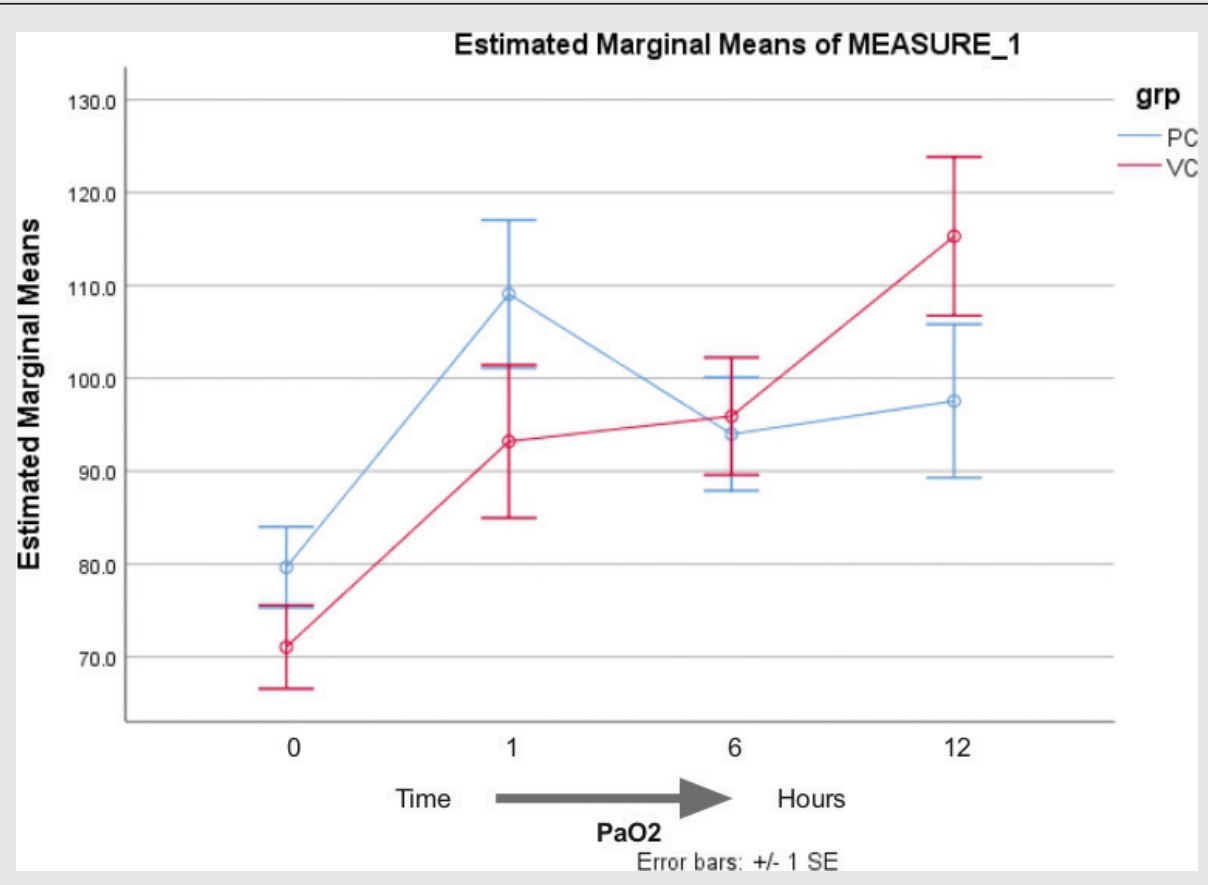




\section{FIGURE 3}

Trend in $\mathrm{PaO}_{2} / \mathrm{FiO}_{2}$ ratio after recruitment in both groups.

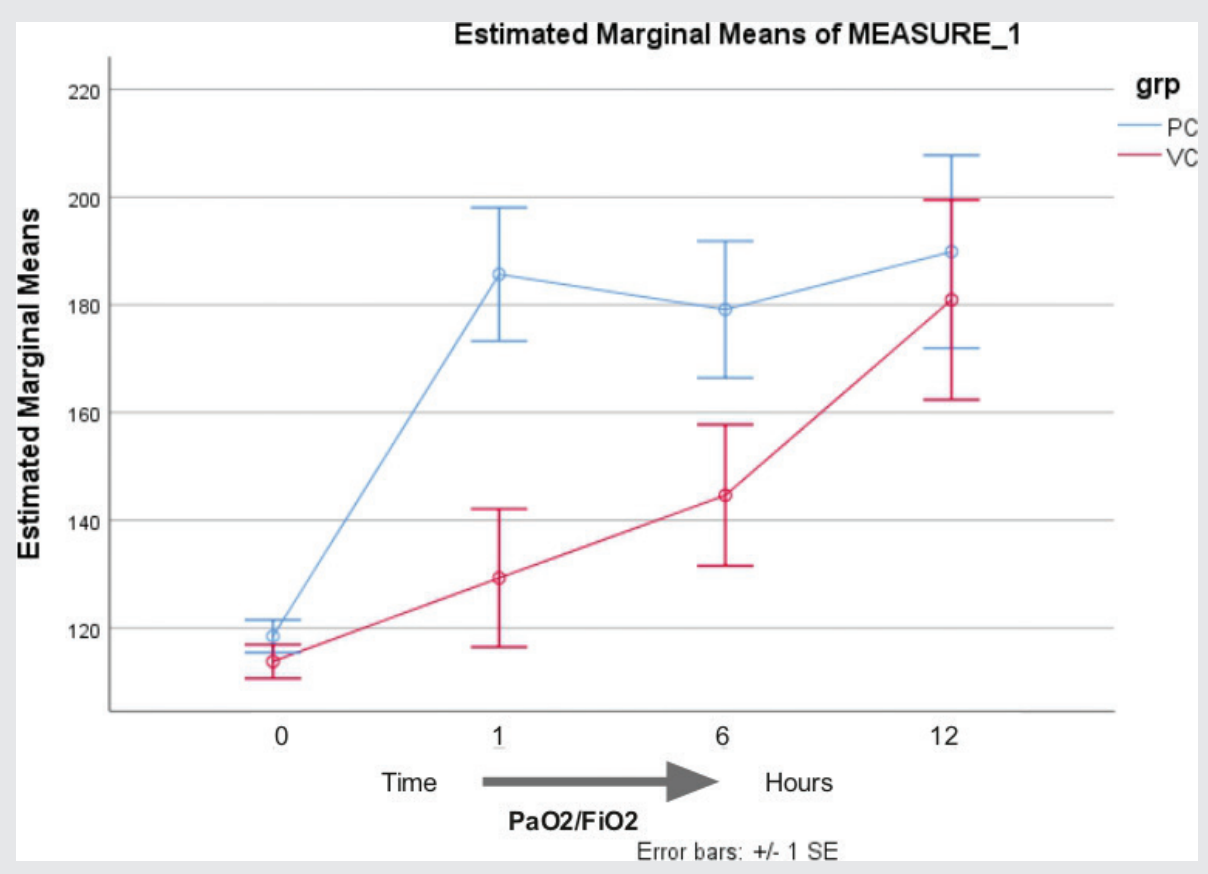

\section{FIGURE 4}

Trend of PEEP after recruitment.

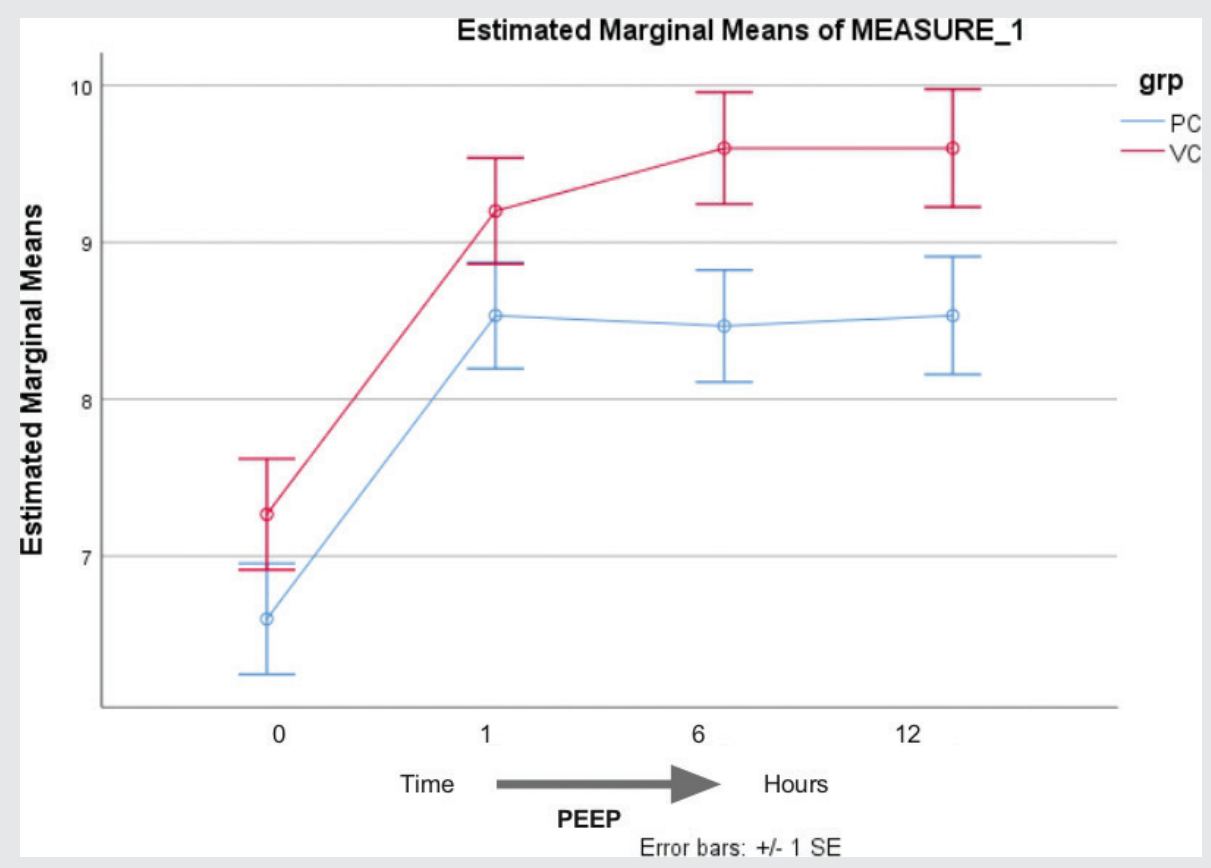


Vibha et al.

\section{FIGURE 5}

Trend of plateau pressure in both groups.

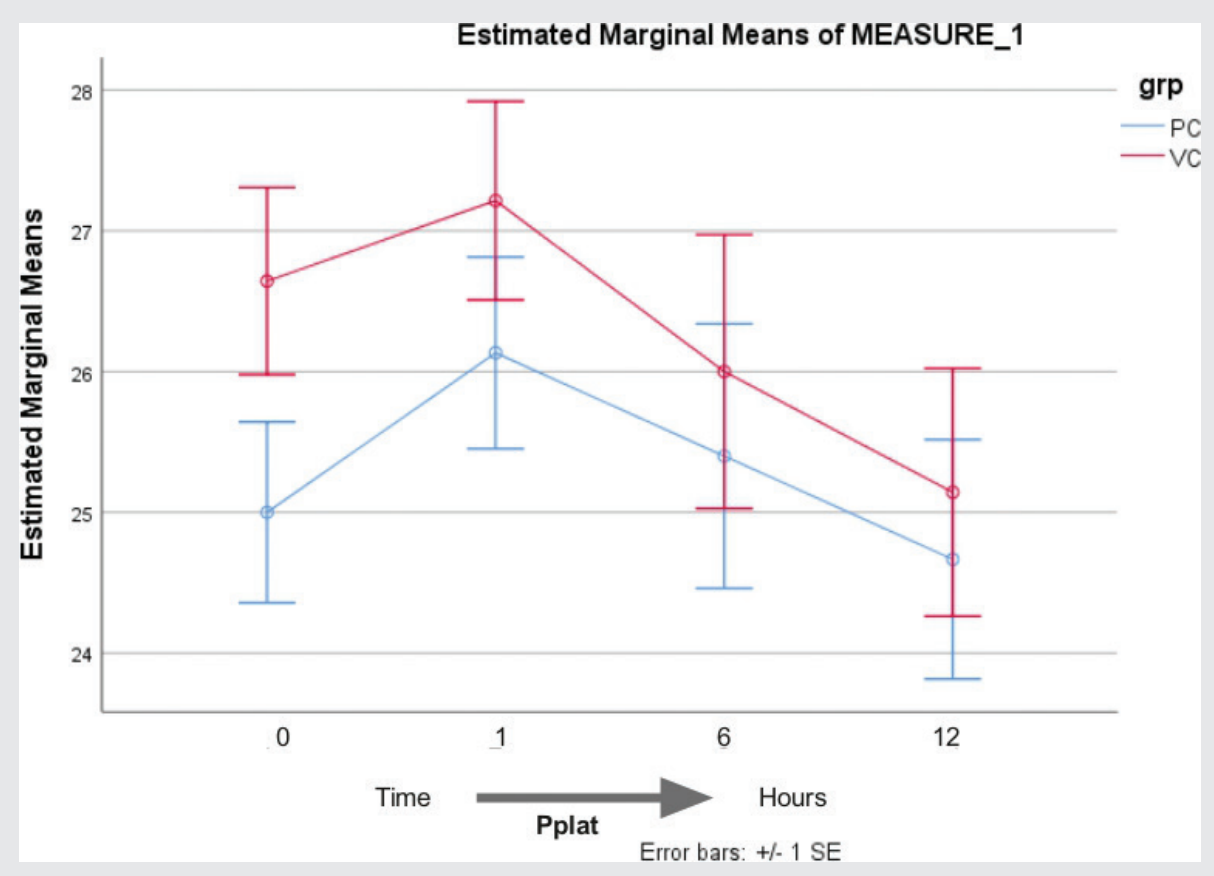

\section{FIGURE 6}

Trend of static compliance in both groups after recruitment.

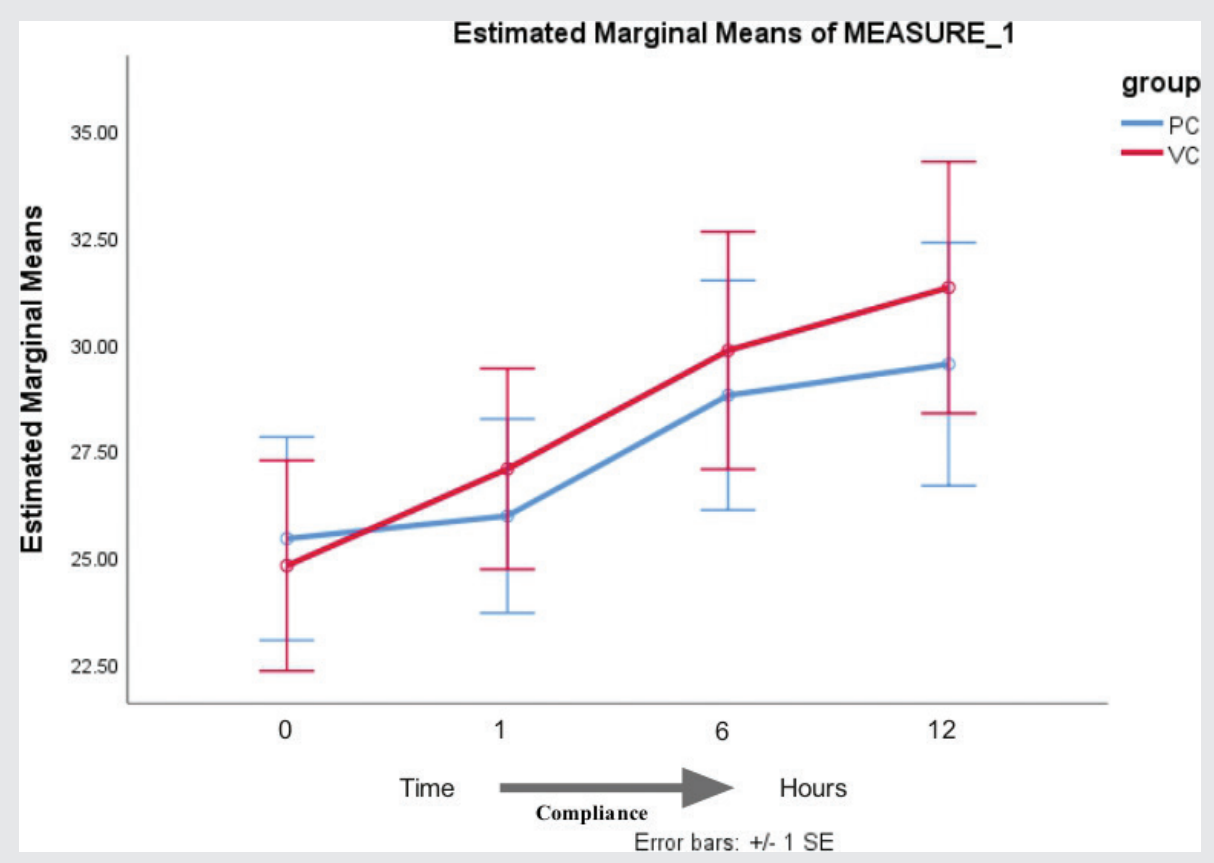


TABLE 3

Heart rate, MAP, and VIS in the patient groups before and after recruitment

\begin{tabular}{|c|c|c|c|c|c|c|}
\hline & & $\mathbf{O h}$ & $1 \mathrm{~h}$ & $6 \mathrm{~h}$ & $12 \mathrm{~h}$ & $P$ \\
\hline \multirow[t]{2}{*}{ Heart Rate } & PCV & $90.60 \pm 11.92$ & $93.93 \pm 20.98$ & $91.13 \pm 16.70$ & $84.73 \pm 16.329$ & 0.70 \\
\hline & VCV & $86.14 \pm 15.34$ & $84.64 \pm 17.64$ & $89.36 \pm 18.20$ & $89.14 \pm 14.759$ & 0.70 \\
\hline$P$ & & 0.38 & 0.21 & 0.78 & 0.45 & \\
\hline \multirow[t]{2}{*}{ MAP } & PCV & $80.67 \pm 9.029$ & $76.93 \pm 8.128$ & $81.53 \pm 7.577$ & $76.33 \pm 5.665$ & 0.07 \\
\hline & VCV & $82.93 \pm 10.709$ & $76.57 \pm 10.234$ & $77.57 \pm 14.929$ & $78.64 \pm 9.492$ & 0.07 \\
\hline$P$ & & 0.54 & 0.91 & 0.37 & 0.42 & \\
\hline \multirow[t]{2}{*}{ VIS } & PCV & $12.27 \pm 10.81$ & $13.27 \pm 12.475$ & $10.93 \pm 10.627$ & $9.07 \pm 9.513$ & 0.18 \\
\hline & VCV & $9.79 \pm 10.98$ & $9.57 \pm 10.082$ & $9.14 \pm 8.839$ & $8.57 \pm 8.976$ & 0.18 \\
\hline$P$ & & 0.54 & 0.39 & 0.62 & 0.88 & \\
\hline
\end{tabular}

Note: " 0 " $h$ values are taken just before recruitment manouvre; $1 \mathrm{~h}, 6 \mathrm{~h}$ and $12 \mathrm{~h}$ values at those at the respective time after recruitment. MAP $=$ mean arterial pressure; $V I S=$ vasopressor inotrope score; $P C V=$ pressure control ventilation; $V C V=$ volume control ventilation.

TABLE 4

Length of mechanical ventilation, ICU stay

\begin{tabular}{lcrc}
\hline Group & PCV & \multicolumn{1}{c}{ VCV } & $P$ \\
\hline LOMV (days) & $10.33 \pm 5.64$ & $8.93 \pm 4.71$ & 0.47 \\
Length of ICU stay (days) & $12.60 \pm 5.98$ & $11.93 \pm 6.37$ & 0.77 \\
\hline
\end{tabular}

LOMV = length of mechanical ventilation; ICU = intensive care unit;

$P C V=$ pressure control ventilation; $V C V=$ volume control ventilation .

\section{TABLE 5}

Patient outcomes on both modes of ventilation

\begin{tabular}{lrcc}
\hline Outcome & PCV & VCV & $\boldsymbol{P}$ \\
\hline Extubation & $2 / 15(13 \%)$ & $1 / 14(7 \%)$ & 0.29 \\
Death & $10 / 15(66 \%)$ & $11 / 14(78 \%)$ & 0.23 \\
LAMA & $3 / 15(20 \%)$ & $2 / 14(14 \%)$ & 0.33 \\
\hline
\end{tabular}

Note: $L A M A$ = left against medical advice; $P C V=$ pressure control ventilation; VCV = volume control ventilation.

end of 6 and $12 \mathrm{~h}$, but this was at the cost of higher PEEP requirement in the VCV group as compared to the PCV group. This could be because, compared with constant flow VCV, PCV favours gas distribution between regions with heterogeneous time constants and allows a more homogeneous share of tidal volume to the whole lung through its quicker alveolar filling and more laminar flow [19]. The initial high flow rate leads to rapid alveolar inflation and improves ventilation-perfusion mismatch [20]. These advantages of PCV over VCV can be accomplished with VCV with a decelerating flow waveform [21]. However, we have used the volume control mode with a constant flow, which could explain the difference.

Similar to early proning in ARDS, early SRM may probably recruit the collapsed alveoli in the early hyaline membrane phase of ARDS before fibroblastic cell activation [22]. We performed the manoeuvre as early as $6 \mathrm{~h}$ after intubation, which probably resulted in the improvement in oxygenation. However, along with improvement in oxygenation, adverse events like hypotension have been reported during the procedure, which is usually transient. Hodgson et al. [12] did not report any adverse hemodynamic events during their study. They performed the SRM once daily whereas Kung et al. [22] performed it every 8 h. Kung et al. [22] reported a $50 \%$ incidence of hypotension during the manoeuvre. They also increased the PEEP by $3 \mathrm{~cm} \mathrm{H} \mathrm{H}_{2} \mathrm{O}$ every 3 breaths, whereas Hodgson et al. [12] increased the PEEP by $10 \mathrm{~cm} \mathrm{H}_{2} \mathrm{O}$ every $2 \mathrm{~min}$. Therefore, the rapid escalation of PEEP and increased frequency of SRM could have contributed to the high incidence of hypotension in their study.

Patients with liver disease exhibit intense arterial vasodilatation with a reduced central blood volume, mimicking hypovolemia, and vascular hypo reactivity. The frequency of vasopressor requirement is also high in patients with liver disease and ARDS [13]; therefore, the frequency was restricted to just once. The procedure had to be abandoned in one patient due to severe hypotension. The rest of the patients tolerated the procedure well, with no rise in vasopressor support after the procedure. The increase in pleural pressure secondary to the increase in airway pressure plays a major role in impeding venous return. However, the transmission of airway pressure to the pleural space may in part depend on the distensibility of the lungs. It has been found that in patients with lung compliance more than $45 \mathrm{~mL} / \mathrm{cm} \mathrm{H}_{2} \mathrm{O}, 37 \%$ of the airway pressure is transmitted to the pleural space, whereas in patients with compliance less than $30 \mathrm{~mL} / \mathrm{cm}$ $\mathrm{H}_{2} \mathrm{O}$ only $24 \%$ of the airway pressure is transmitted to the pleural space [23]. This could be the reason we did not see an increase in vasopressor support despite a significant increase in PEEP after the SRM.

As evidenced by the high mortality in our study, the physiological improvements did not translate into clinically meaningful outcomes. However, it could have implications for use in patients with other critically ill patients with mild ARDS awaiting liver transplant or in immediate post-liver transplant patients who develop ARDS.

\section{LIMITATIONS}

The main drawback is the pilot study with small sample size. There was a lack of recording of other factors like effusions, degree of ascites, and the presence of hepatopulmonary syndrome that could have influenced the oxygenation and ventilator requirements in both groups.

\section{CONCLUSION}

This study shows that stepwise recruitment manoeuvre is an effective rescue therapy to improve oxygenation in cirrhosis with moderate ARDS. It should be performed as early as possible and even a single manoeuvre is effective. Pressure control ventilation may have an advantage over volume control ventilation in terms of better oxygenation with a lower PEEP requirement. However, a larger sample size could confirm this more substantially.

\section{AUTHOR DISCLOSURES}

\section{Contributors}

All authors contributed to the conception or design of the work, the acquisition, analysis, or interpretation of the data. All authors were involved in drafting and commenting on the paper and have approved the final version.

Funding

This study did not receive any specific grant from funding agencies in the public, commercial, or not-for-profit sectors.

\section{Competing interests}

All authors have completed the ICMJE uniform disclosure form at www. icmje.org/coi_disclosure.pdf and declare: no financial relationships with any organizations that might have an interest in the submitted work in the previous 3 years; no other relationships or activities that could appear to have influenced the submitted work. 


\section{Ethical approval}

This prospective, pilot randomised controlled trial was conducted after approval by the Institutional Ethics Committee (Number: IEC/2017/51/ NA07) from 1st October 2017 to 30th January 2018. All patients gave written informed consent.

\section{REFERENCES}

1. Karcz M, Bankey B, Schwaiberger D, Lachmann B, Papadakos PJ. Acute respiratory failure complicating advanced liver disease. SeminRespirCrit Care Med 2012;33:96-112. doi: 10.1055/s-0032-1301738

2. Olson C. Jody. Intensive care of the patient with cirrhosis. Hepatology 2011;54(5):1864-72. doi: 10.1002/hep.24622

3. Grinnan DC, Truwit JD. Clinical review: respiratory mechanics in spontaneous and assisted ventilation. Crit Care 2005;9:472-84. doi: $10.1186 / \operatorname{cc} 3516$

4. Sharma B, Kumar A, Sethi N, Sood J, Malhotra S, Sarangi R. Changes in respiratory mechanics during extraperitoneal insufflation in inguinal hernia surgery. Indian J Anaesth 2017;61:843-5. doi: 10.4103/ija.IJA_139_17

5. Amato MBP, Barbas CSV, Medeiros DM, et al. Effect of a protective-ventilation strategy on mortality in the acute respiratory distress syndrome. New Engl J Med 1998;338:347-354. doi: 10.1056/ NEJM199802053380602

6. Bajaj P. Ventilator-induced lung injury. Indian J Anaesth 2008;52:363.

7. Chacko B, Peter JV, Tharyan P, John G, Jeyaseelan L. Pressure-controlled versus volume-controlled ventilation for acute respiratory failure due to acute lung injury (ALI) or acute respiratory distress syndrome (ARDS). Cochrane Database Syst Rev 2015;1:CD008807. doi: 10.1002/14651858. CD008807.pub2

8. Lachmann B. Open up the lung and keep the lung open. Intensive Care Med 1992;18:319-21. doi: 10.1007/BF01694358

9. Cipulli F, Vasques F, Duscio E, Romitti F, Quintel M, Gattinoni L. Atelectrauma or volutrauma: the dilemma. J Thorac Dis 2018;10:1258-64. doi: $10.21037 /$ jtd.2018.02.71

10. Pensier J, de Jong A, Hajjej Z, et al. Effect of lung recruitment maneuver on oxygenation, physiological parameters and mortality in acute respiratory distress syndrome patients: a systematic review and meta-analysis. Intensive Care Med 2019;45:1691-702. doi: 10.1007/s00134-019-05821-9

11. Findlay JY, Fix OK, Paugam-Burtz C, et al. Critical care of the end-stage liver disease patient awaiting liver transplantation. Liver Transpl 2011;17(5):496-510. doi: 10.1002/lt.22269

12. Vallabhajosyula S, Jentzer JC, Kotecha AA et al. Development and performance of a novel vasopressor-driven mortality prediction model in septic shock. Ann Intensive Care 2018;8:112. doi: 10.1186/ s13613-018-0459-6

13. Boente RD, Sheikh A, Bosslet GT, Ghabril MS. Outcomes of acute respiratory distress syndrome in mechanically ventilated patients with cirrhosis. Crit Care Explor 2019;1:e0040. doi: 10.1097/CCE.0000000000000040

14. Donahoe M. Acute respiratory distress syndrome: a clinical review. Pulm Circ 2011;1:192-211. doi: 10.4103/2045-8932.83454

15. Hodgson CL, Tuxen DV, Davies AR, et al. A randomised controlled trial of an open lung strategy with staircase recruitment titrated PEEP and targeted low airway pressures in patients with acute respiratory distress syndrome. Crit Care 2011;15(3):R133. doi: 10.1186/cc10249

16. Guerin C, Debord S, Leray V, et al. Efficacy and safety of recruitment maneuvers in acute respiratory distress syndrome. Ann Intensive Care 2011;1:9. doi: 10.1186/2110-5820-1-9

17. Pelosi $\mathrm{P}$, Cadringher P, Bottino N, et al. Sigh in acute respiratory distress syndrome. Am J Respir Crit Care Med 1999;159:872-80. doi: 10.1164/ ajrccm.159.3.9802090

18. Grasso S, Stripoli T, Sacchi M, et al. Inhomogeneity of lung parenchyma during the open lung strategy: a computed tomography scan study. Am J Respir Crit Care Med 2009;180:415-23. doi: 10.1164/rccm. 200901-0156OC

19. Prella M, Feihl F, Domenighetti G. Effects of short-term pressurecontrolled ventilation on gas exchange, airway pressures, and gas distribution in patients with acute lung injury/ARDS: comparison with volume-controlled ventilation Chest 2002;122:1382-8. doi: 10.1378/ chest.122.4.1382

20. Movassagi R, Montazer M, Mahmoodpoor A, Fattahi V, Iranpour A, Sanaie S. Comparison of pressure vs. volume controlled ventilation on oxygenation parameters of obese patients undergoing laparoscopic cholecystectomy. Pak J Med Sci 2017;33:1117-22. doi: 10.12669/pjms. 335.13316

21. Davis K Jr, Branson RD, Campbell RS, Porembka DT. Comparison of volume control and pressure control ventilation: is flow waveform the difference? J Trauma 1996;41:808-14. doi: 10.1097/00005373-19961100000007

22. Kung SC, Hung YL, Chen WL, Wang CM, Chang HC, Liu WL. Effects of stepwise lung recruitment maneuvers in patients with early acute respiratory distress syndrome: a prospective, randomized, controlled trial. J Clin Med 2019;8:231. doi: 10.3390/jcm8020231

23. Jardin F, Genevray B, Brun-Ney D, Bourdarias JP. Influence of lung and chest wall compliances on transmission of airway pressure to the pleural space in critically ill patients. Chest 1985;88:653-8. doi: $10.1378 /$ chest.88.5.653 